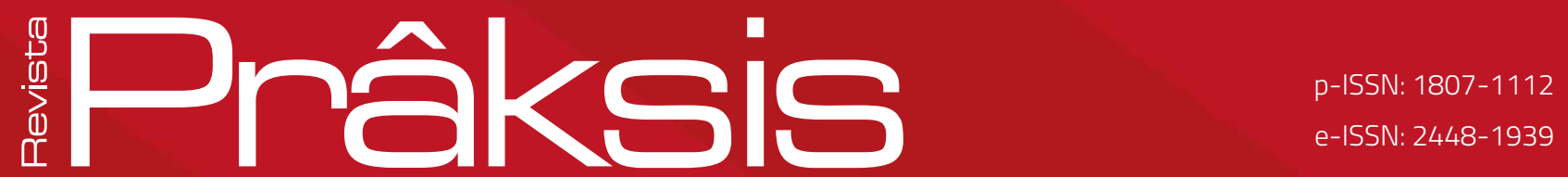

Recebido em: 12 de março de 2019

Aprovado em: 05 de julho de 2019

Sistema de Avaliação: Double Blind Review

RPR |a. $16 \mid$ n. 3 |p. 137-154| set./dez. 2019

DOI: https://doi.org/10.25112/rpr.v3i0.1917

\title{
COMO PROBLEMATIZAR AS VIOLÊNCIAS DE GÊNERO NA EDUCAÇÃo INFANTIL? UMA pROpOsta EM DISCUSSÃO
}

\section{HOW TO PROBLEMATIZE GENDER VIOLENCES IN CHILD EDUCATION? A DISCUSSION PROPOSAL}

\section{Jane Felipe}

Pós-doutora na área de Cultura Visual, pela Universidad de Barcelona. Doutora em Educação pela Universidade Federal do Rio Grande do Sul. Professora titular da Faculdade de Educação da UFRGS.

E-mail: janefelipe.souza@gmail.com

\section{Jéssica Tairâne Moraes}

Mestranda em Educação pela Universidade Federal do Rio Grande do Sul. Professora das redes públicas de ensino das cidades de Novo Hamburgo e São Leopoldo.

E-mail: jetairane@gmail.com 


\section{RESUMO}

Este trabalho tem por objetivo discutir as violências de gênero e suas implicações e consequências na Educação Infantil, pois muitas crianças vivenciam situações de violência intrafamiliar. Nosso compromisso como educadores/as tem sido problematizar o tema, tendo como referencial teórico os Estudos de Gênero e os Estudos Culturais. Para tanto, realizamos um trabalho contínuo com crianças de quatro e cinco anos, em uma EMEI de Novo Hamburgo/RS, sobre Direitos Humanos e equidade de gênero, promovendo atividades lúdicas e leituras literárias, que visam discutir a divisão do trabalho doméstico, modos de resolução de conflitos e o respeito às diferenças. Os resultados apontam que as crianças foram (re)construindo alguns scripts de gênero, trazendo soluções para as divisões de tarefas.

Palauras-chave: Violências de gênero. Educação Infantil. Scripts de gênero. Prática pedagógica.

\section{ABSTRACT}

This work aims to discuss gender violence and its implications and consequences in Early Childhood Education, since many children experience situations of intrafamily violence. Our commitment as educators has been to problematize the theme, having as theoretical reference the Studies of Gender and Cultural Studies. For that, we carried out a continuous work with children of four and five years, in an EMEI of Novo Hamburgo / RS, on Human Rights and gender equality, promoting play activities and literary readings, that aim to discuss the division of domestic work, ways of conflict resolution and respect for differences. The results show that children have been (re) constructing some gender scripts, bringing solutions to task divisions.

Keywords: Gender violence. Child education. Gender scripts. Pedagogical practice. 


\section{INTRODUÇÃO}

Vivemos em uma sociedade em que os altos índices de violência de gênero e desigualdade entre homens e mulheres se fazem presentes. Frente a tal situação, seguidamente, a escola se torna um ambiente por onde perpassam tais questões e que são expressas pelas crianças e famílias.

Diante da Constituição Federal de 1988, bem como das Diretrizes Curriculares Nacionais para a Educação em Direitos Humanos (2012), a escola assume o compromisso de tensionar, junto às crianças, toda e qualquer forma de preconceito, discriminação e violência. Dessa forma, o objetivo principal deste estudo é problematizar com as crianças da Educação Infantil as questões que envolvem as diversidades, as desigualdades e as violências, colocando sob suspeita alguns scripts de gênero que atravessam a infância contemporânea. Pensando nisso, este artigo apresenta um recorte de pesquisa a partir da proposta pedagógica desenvolvida em uma escola pública do município de Novo Hamburgo com crianças entre 4 e 5 anos de idade. A referida proposta procurou ouvi-las sobre suas interpretações acerca das situações de violência e desigualdade que vivenciam no cotidiano.

Diante do exposto, ressaltamos que procuramos desenvolver uma educação que potencializasse certa preparação das meninas para reconhecerem situações que possam enredá-las em alguma situação de violência. Além disso, possibilitamos reflexões para que meninos e meninas pudessem analisar as experiências desiguais de gênero vivenciadas em nossa sociedade.

Assim, dividimos o artigo em três eixos de discussão: a) o contexto das violências; b) apresentação e discussão das propostas realizadas com as crianças; c) a importância de debater na escola os temas aqui já referidos como uma questão de direitos humanos.

\section{VISUALIZANDO O CONTEXTO}

Segundo a Organização Mundial da Saúde (OMS), em seu sentido etimológico, a palavra violência deriva do latim violentia, que caracteriza o que é violento, através da coação ou constrangimento físico e moral. De maneira ampla, a OMS define violência como "o uso deliberado da força física (ou do poder), seja na forma de ameaça, ou efetiva contra si mesmo, ou outra pessoa ou grupo ou comunidade, causando ou com probabilidade de causar lesões, morte, danos psicológicos, transtornos psicológicos ou privações".

A violência é um fenômeno social presente em todas as classes sociais e culturas, pois faz parte de um processo civilizatório estruturante da sociedade. Por isso, antes de lançar algumas reflexões sobre a participação das crianças sob a ótica da violência e dos seus mais variados tipos, acreditamos ser relevante trazer algumas considerações capazes de mostrar a sua complexidade e amplitude, pincipalmente em 
como a violência ocorrida nas famílias se relaciona com a infância e as crianças, que são parceiras na construção dessa pesquisa.

No que se refere à violência que ocorre no âmbito familiar, o Ministério da Saúde (2001: s.p.) define que ela é

Toda ação ou omissão cometida por um membro familiar que prejudique o bem-estar, a integridade física, psicológica ou a liberdade e o direito ao pleno desenvolvimento de outro membro. Pode ser cometida dentro ou fora de casa por algum membro da família, incluindo as pessoas que passam a assumir função parental, ainda que sem laços de consanguinidade.

Lívia Sacramento e Manuel Rezende (2016) lembram que o termo violência contra a mulher foi dado pelo movimento feminista há pouco mais de trinta anos. Esse é um tipo de violência que, na grande maioria dos casos, ocorre entre pessoas próximas ou que moram na mesma casa, configurando-se, também, como violência doméstica. $E$ isso afeta muitas pessoas que convivem com os envolvidos, principalmente as crianças. Os autores destacam ainda que a violência doméstica está tão presente na vida de algumas pessoas que, por diversas vezes, pode ser interpretada como algo natural. Assim, entende-se que a violência doméstica ou intrafamiliar se caracteriza por toda ação ou omissão que prejudique o bem-estar, a liberdade e a integridade de qualquer membro do ambiente doméstico/família, que, na maioria dos casos, ocorre contra mulheres, crianças e idosos/as. Dessa forma, é possível afirmar que "são as questões de gênero, vinculadas às desigualdades, que revestem as agressões e os abusos perpetrados contra as mulheres e as meninas que tornam a violência contra a mulher um evento específico" (SACRAMENTO; REZENDE, 2016: 97).

Os casos de violências contra as mulheres em todo o Brasil são alarmantes. Segundo dados do Mapa da violência 2015: Homicídio de mulheres no Brasil, o país é o quinto com incidência de violência contra a mulher, no ranking mundial de 83 países.

Segundo balanço realizado pela Central de Atendimento à Mulher - Ligue 180, no primeiro semestre do ano de 2016 foram registrados 67.962 relatos de violência contra a mulher, sendo eles: 34.703 relatos de violência física $(51,06 \%) ; 21.137$ relatos de violência psicológica $(31,10 \%) ; 4.421$ relatos de violência moral $(6,51 \%) ; 3.301$ relatos de cárcere privado $(4,86 \%) 2.921$ relatos de violência sexual $(4,30 \%) ; 1.313$ relatos de violência patrimonial (1,93\%); 166 relatos de tráfico de pessoas $(0,24 \%)$. 
Outros dados relevantes desse mesmo balanço é que $67,63 \%$ das violências foram cometidas por homens em relações heteroafetivas, sendo que em 39,34\% dos casos a violência é diária e em 32,76\% é semanal - o que equivale a $71,10 \%$ de casos de violência com uma grande frequência; $78,72 \%$ das vítimas de violência doméstica possuem filhos/as e 59,95\% destes presenciam ou presenciaram a(s) agressão/ agressões e $22,91 \%$ sofrem ou sofreram violência.

Diante desse contexto, fica notório o quanto é emergente que a violência contra a mulher seja desnaturalizada e que esse debate esteja presente na escola, uma vez que as crianças filhas das vítimas presenciam e também sofrem violências e, por vezes, acabam reproduzindo tais comportamentos no ambiente escolar e nas suas relações, justamente pelo fato da violência ser tida como algo "natural" para muitas famílias. E, quando se fala em violências, é importante considerar que elas se tratam, conforme aponta Constantina Xavier Filha (2015: 1574), de

Um fenômeno complexo e dinâmico, social e histórico, na medida em que tem como seu espaço de criação e desenvolvimento a sociedade em sua relação entre sujeitos. $A$ violência, portanto, deve ser compreendida como produto de um sistema complexo de relações, historicamente construído e multifacetado, que envolve diferentes realidades de uma sociedade (familiar, social, econômica, ética, jurídica, política etc.), produzidas em uma cultura, permeadas por valores e sentidos culturais.

Segundo Galvão e Andrade (2004, p. 91), "a violência constitui-se em um dos mecanismos de dominação do homem sobre a mulher, legitimado por instituições como a família e o casamento" e, nesse contexto, também é possível encontrar dados de violência de gênero contra meninas no âmbito familiar e não somente em relações heteroafetivas. A exemplo disso, consideramos importante trazer alguns dados da pesquisa Por ser menina no Brasil, realizada pela PLAN, mostrando o quanto as desigualdades entre os gêneros começam a se delinear no espaço doméstico. Os dados da referida pesquisa mostram que:

- 76,3\% das meninas responderam que são cuidadas pela mãe quando não estão na escola, o que só confirma o quanto ainda cuidar das crianças é visto como uma tarefa "essencialmente" feminina, indicando, segundo Felipe (2018), uma oitava jornada de trabalho para muitas mulheres;

- Em relação às tarefas domésticas, 81,4\% das meninas são responsáveis por arrumar a própria cama, $41 \%$ em cozinhar, $76,8 \%$ lavar a louça e $65,6 \%$ por limpar a casa, enquanto apenas $11,6 \%$ dos seus irmãos arrumam a cama, 11,4\% cozinham, 12,5\% lavam a louça e 11,4\% limpam a casa. Isso demonstra 
a desigualdade de gênero presente no espaço doméstico, pois o simples fato de serem meninas, já as coloca como responsáveis pelas tarefas do lar, retirando delas o tempo para brincadeiras. 31,7\% das meninas entrevistadas afirmaram ser insuficiente o tempo para brincar durante a semana. Em relação a essa questão, o Instituto Brasileiro de Geografia e Estatística (IBGE) apresenta dados sobre o número médio de horas semanais dedicadas aos cuidados de pessoas e/ou afazeres domésticos, por sexo: no ano de 2016 , cerca de $73 \%$ a mais de horas do que os homens (18,1 horas contra 10,5 horas). Também se constata que as mulheres pretas ou pardas são as que mais se dedicam aos cuidados de pessoas e/ou aos afazeres domésticos, com o registro de 18,6 horas semanais no mesmo ano.

- Quando questionadas sobre a atitude dos pais ou responsáveis quando elas fazem algo de errado: $57,1 \%$ apontam que eles conversam com elas; $41,8 \%$ das famílias as admoestam; em $26,2 \%$ dos casos os pais gritam com elas; e em $23,2 \%$ dos casos as famílias usam de violência física.

Diante dessa realidade, fica evidente que a violência também se volta contra as meninas no espaço familiar, sendo que, desse modo, conclui-se que uma em cada quatro meninas sofre violência física em casa. No entanto, na mesma pesquisa, $87,4 \%$ das meninas dizem se sentir amadas e bem tratadas em casa, o que demonstra que a maioria não reconhece a violência sofrida. Outro documento que mostra de forma bastante evidente as violências contra crianças e mulheres no Brasil é o Atlas da Violência 2018, produzido pelo Instituto de Pesquisa e Estatística Aplicada (Ipea) e pelo Fórum Brasileiro de Segurança Pública (FBSP). Ele nos mostra que, em 2016, 4.645 mulheres foram assassinadas no país, representando uma taxa de 4,5 homicídios para cada 100 mil brasileiras. Em dez anos, é possível observar um aumento de $6,4 \%$.

Todo esse cenário é preocupante, uma vez que, conforme afirmam Jane Felipe e Carmen Galet (2016, p. 85), "antes da agressão física propriamente, há um longo, contínuo e sistemático processo de agressão moral e psicológica, que compromete a autoestima das mulheres, afetando também meninas e meninos que convivem com este cenário de desrespeito em seus lares". Frente a tal situação, o documento (IPEA, 2018, p. 46) considera que

A base de dados do Sistema de Informações sobre Mortalidade não fornece informação sobre feminicídio, portanto não é possível identificar a parcela que corresponde a vítimas desse tipo específico de crime. No entanto, a mulher que se torna uma vítima fatal muitas vezes já foi vítima de uma série de outras violências de gênero, por exemplo: violência psicológica, patrimonial, física ou sexual. 
O mesmo Atlas ainda traz dados de pesquisa sobre os casos de estupros registrados em 2016, perfazendo um total de 49.497 casos nas polícias brasileiras e as crianças vêm sendo as vítimas de pelo menos metade dos casos ao longo dos anos.

Um dos dados mais preocupantes é constatar que as crianças são as maiores vítimas nos casos de estupros coletivos, que corresponde a cerca de $43,7 \%$ dos casos.

O que chama atenção também é o grau de parentesco das vítimas de acordo com a faixa etária: no estupro de adultos, agressores do maior número de casos são desconhecidos (53,52\%), seguido de amigos e conhecidos (18,82\%). Já no caso das crianças até 13 anos de idade, os maiores agressores são amigos e conhecidos da família $(30,13 \%)$, seguido de padrastos $(12,09 \%)$ e do próprio pai $(12,03 \%)$.

Esses dados divulgados, além de todas as violências que mulheres e crianças sofrem, nos convocam a olhar com mais atenção para a violência sexual contra as crianças, principalmente entre as meninas, que vem crescendo de maneira muito alarmante nos últimos anos, conforme mais alguns dados estatísticos apresentados na sequência.

\section{CRESCIMENTO DA VIOLÊNCIA SEXUAL CONTRA CRIANÇAS NA ÚLTIMA DÉCADA}

Segundo boletim epidemiológico divulgado em 2018 pelo Ministério da Saúde, o Brasil teve um aumento de $83 \%$ nas notificações gerais de violências sexuais contra crianças e adolescentes entre os anos de 2011 e 2017. A maioria das ocorrências mostra que a violência ocorreu dentro da própria casa, praticada por pessoas muito próximas às crianças e, em muitos casos, tal fato se deu mais de uma vez.

Em entrevista ao site G1, Itamar Gonçalves, da ONG Childhood Brasil, fala sobre a necessidade de se criar, no Brasil, espaços e ações de prevenção que abordem temas sobre o conhecimento do corpo, questões de gênero e os padrões acerca das masculinidades e feminilidades, visando o empoderamento das crianças. Na mesma matéria também consta a informação de que o Ministério da Saúde considera violência sexual os casos de assédio, estupro, pornografia infantil e exploração sexual. 0 estupro foi o caso mais notificado dentre todas as violências cometidas contra crianças e adolescentes $(62,0 \%$ em crianças e 70,4\% em adolescentes). Entre as crianças, o maior número de casos de violência sexual acontece com crianças entre 1 e 5 anos (51,2\%). Já entre os adolescentes, são entre os 10 e 14 anos $(67,8 \%)$. Outro dado que chama a atenção é que a maioria das vítimas são negros e mulheres. Tanto entre adolescentes quanto crianças, as vítimas negras tiveram a maior parte das notificações $(55,5 \%$ e $45,5 \%$, respectivamente). Também são a maioria entre as vítimas da violência sexual as crianças do sexo feminino. $74,2 \%$ das crianças são meninas $92,4 \%$ são as jovens adolescentes. 
O mesmo estudo mostra que a maioria dos casos de violência sexual contra crianças e adolescentes são cometidos por homens: nos casos envolvendo adolescentes, em 92,4\% das notificações o agressor era do sexo masculino. Nos casos envolvendo crianças, em $81,6 \%$. Segundo o boletim do Ministério da Saúde, torna-se imprescindivel problematizar a situação, já que a violência pode ser reflexo de uma cultura do machismo. Outra emergência é que o uso da força deixe de ser um padrão de socialização na educação dos meninos. Torna-se necessário que problematizemos o fato de que os meninos são culturalmente ensinados a dominar as meninas e, mais tarde, as mulheres.

Apesar do aumento de 83\%, o Ministério da Saúde acredita que muitos casos não são notificados, pois o Sistema de Vigilância de Violências e Acidentes (Viva), que foi desenvolvido pelo próprio Ministério, ainda não está implementado em todo o país. E apenas em 2014 os casos de violência sexual passaram a ser imediatamente notificados, devendo ser comunicados à Secretaria Municipal de Saúde em até 24 horas após o atendimento da vítima. Considerando que o Viva não está em todos os lugares do Brasil, podemos depreender que os grandes centros urbanos com maiores recursos tendem a uma maior organização estatística de notificação. Observa-se ainda que os maiores casos de notificações estão nas regiões Sudeste $(40,4 \%)$ e Sul $(21,7 \%)$ para as crianças e Sudeste $(32,1 \%)$ e Norte $(21,9 \%)$ para os adolescentes.

$O$ Estatuto da Criança e do Adolescente (ECA) - Lei 8.069/90 - estabelece em seu artigo $5^{\circ}$ que "nenhuma criança ou adolescente será objeto de qualquer forma de negligência, discriminação, exploração, violência, crueldade e opressão [...]". Entretanto, todos esses dados demonstram que as violências ameaçam o direito à vida e à saúde das crianças e que, por isso, debates sobre o tema são necessários na escola, para que elas possam estar atentas a essa questão. É fundamental que as crianças saibam reconhecer quanto estão presenciando ou sendo vítimas de algum tipo de violência e, principalmente, para que sejam incentivadas ao diálogo para a resolução dos conflitos. Portanto, algumas propostas de discussão e tensionamento sobre o tema realizadas com as crianças serão brevemente apresentados na seção seguinte.

\section{APRESENTANDO A PROPOSTA DESENVOLVIDA COM AS CRIANÇAS}

As teorizações sobre literatura e discurso permitiram-me perceber o caráter construído e construcionista da literatura, mas principalmente, o quanto a linguagem nos produz, nos governa, nos seduz. Não podemos situar nada fora dela, e por tal razão as lutas pela posse de discursos tornam-se vitais na pós-modernidade. (Argüello, 2013, p.121) 
Partindo do conceito de poder implícito nos discursos que nos constituem e são potencializados em artefatos, como livros e imagens, tivemos como intenção operar com discussões que colocassem sob suspeita as situações que nos interpelam, contribuindo na produção de meninos e meninas/ homens e mulheres.

Dessa forma, para potencializar as reflexões, foi preparada uma caixa contendo imagens de homens e mulheres executando tarefas, tais como: cuidar das crianças, limpar a casa, lavar a louça.

Em um clima de suspense e surpresa, na medida em que as imagens foram sendo retiradas da caixa pelas próprias crianças, as discussões começaram a surgir. Discursos como: "Homem pode lavar a louça?"; "Meu pai me cuida!"; "Lá em casa os homens não ajudam a limpar a casa" foram grandes propulsores de problematizações. Contudo, falas como: "Enquanto o homem lava a louça a mulher pode varrer a casa"; "Homem pode cozinhar e cuidar de nós"também foram sendo expressas. Em seguida, com vassoura e pás, as crianças da turma foram convidadas a brincar de casinha no pátio da escola e realizaram a experiência de varrer o ambiente no qual brincavam.

Posteriormente, buscamos a literatura para discutir a temática de gênero e maus-tratos emocionais. Realizamos tal escolha por saber que os textos literários não são neutros, e sim carregados de produção de significados e de mensagens que podem ser entendidas como dispositivos que contribuem para a construção da empatia nos sujeitos. Assim, utilizamos a obra "Arthur e Clementina" (TURIN, 2001), que foi contada para as crianças, fomentando discussões. 0 texto narra uma história de duas tartarugas, na qual a personagem feminina - a Clementina - vive uma situação de desigualdade. Além disso, a personagem é inferiorizada por seu marido Arthur.

A partir da narrativa, as crianças trouxeram relatos que exaltavam as capacidades de ambos os gêneros. Além disso, todos se posicionaram contra a situação abusiva vivida pela personagem Clementina, o que demonstra o quanto as crianças são capazes de se posicionarem contra as situações abusivas e de desigualdade. Após nossas discussões, a turma foi surpreendida com a visita de uma tartaruga, batizada de "Clementina".

Conforme afirma Felipe (2014), quando falamos de violência contra mulheres e crianças, geralmente se pensa na violência que é visível, que deixa marcas no corpo. No entanto,

Antes de chegarmos a esse nível de violência, nos deparamos com uma sucessão de situações que envolvem a violência psicológica ou maus-tratos emocionais. Esse tipo de violência se caracteriza por uma série de comportamentos que envolvem a rejeição e a depreciação constantes, ridicularizando e humilhando, discriminando de alguma 
forma, numa clara ação de desrespeito, impondo, muitas vezes, o isolamento de amigos e parentes. [...] A ameaça de morte e as perseguições [...] implicam no cerceamento de liberdade de ir e vir, instalando o medo e a fragilidade emocional (FELIPE; GALET, 2014, p. 7).

Portanto, torna-se emergente e necessário, sim, que se invista em discussões desse cunho com as crianças ainda pequenas e a escola é um dos espaços que pode promover esse debate. A partir das experiências relatadas conseguimos perceber o quanto se faz importante discutir as temáticas de gênero e violência com as crianças, que possuem grande potencial de problematização.

No que se refere a essa importância de debater as questões sobre violências com as crianças, tornase relevante trazer aqui dados do Fundo das Nações Unidas para a Infância (Unicef) que nos mostra que, no mundo, três quartos das crianças de 2 a 4 anos de idade (o que equivale a cerca de 300 milhões) sofrem violência psicológica ou punição física de seus cuidadores. E uma em cada quatro crianças menores de cinco anos convive com uma mãe vítima de violência doméstica (o que corresponde cerca de 177 milhões). Essa situação reforça o quanto as crianças que ainda se encontram na primeira infância - e muitas delas já frequentam a escola - convivem e sofrem com a violência diariamente, seja contra elas mesmas ou contra a mãe.

Cabe ressaltar que, em função dessa situação, muitas vezes, a crianças acaba considerando a violência como um método para a resolução dos seus conflitos. Por isso, diante desse contexto que as crianças, das mais diversas infâncias, do mundo todo, estão fazendo parte atualmente, é que consideramos a escola com um potencial de espaço de fuga. Em que profissionais possam estar preparados/as e sensibilizados/ as para ouvir o que, muitas vezes, elas não expressam verbalmente, mas sinalizam nas brincadeiras, nos gestos, na interação com o outro. Precisamos acolher o que elas têm a nos contar. Por mais, como diria Jorge Larrosa (2010), que a infância seja um tesouro oculto que o nosso olhar de adulto jamais consegue alcançar, o cenário atual nos mostra a urgência de encontrarmos estratégias de conseguir ouvir as crianças e o que elas têm a nos dizer sobre o mundo, que por diversas vezes as violenta.

Dessa forma, parafraseando Argüello (2013), não se trata de ter a expectativa de mudar o comportamento ou a opinião das crianças sobre o tema das desigualdades, mas colocá-las em contato com belas histórias, ricas na sua visualidade e na sua linguagem, a fim de discutir com elas as temáticas de gênero, em especial as situações de violência.

Por meio das experiências propostas, foi possivel observar que as discussões provocaram na turma a desestabilização de alguns scripts de gênero tidos como essenciais e que colocam o sujeito feminino 
numa posição de subordinação e o homem em situação privilegiada. As soluções trazidas pelas crianças para as questões referentes às divisões de tarefas, também revelam o potencial infantil na busca de igualdade entre os sujeitos.

Assim, pontuamos que ações como essas nos apresentam alguns caminhos nos quais podemos percorrer, na busca de uma educação para a equidade de gênero. Nessa direção, na próxima seção apresentamos algumas considerações sobre a inserção desses debates na escola não apenas como algo importante, mas como uma questão de Direitos Humanos.

\section{ALGUMAS CONSIDERAÇÕES SOBRE DISCUTIR VIOLÊNCIAS DE GÊNERO NA ESCOLA: UMA QUESTÃO DE DIREITOS HUMANOS}

Segundo a Declaração Universal do Direitos Humanos, em seu artigo 1, "Todos os seres humanos nascem livres e iguais em dignidade e direitos. São dotados de razão e consciência e devem agir em relação uns aos outros com espirito de fraternidade".

Os Direitos Humanos são fundamentais para a ampliação do caráter democrático de uma sociedade e para que as pessoas consigam exercer seu direito à cidadania. Conforme aponta Joaquin Flores (2009, p. 19), eles podem ser conceituados como "processos institucionais e sociais que possibilitam a abertura e a consolidação de espaços de luta pela dignidade humana".

É inegável que as violências cometidas contra mulheres e crianças estão diretamente relacionadas a esses temas, uma vez que a produção social, histórica e cultural das desigualdades de gênero tem alimentado esse quadro, colocando as mulheres em desvantagem e, em consequência, aos seus/ suas filhos/as. Entretanto, para que possamos refletir sobre tal quadro de maneira potente, torna-se indispensável que docentes estejam preparados e sensibilizados para abordar o tema da violência e das relações desiguais de poder com as crianças, assim como é necessário que o currículo das escolas seja capaz de acolher e alicerçar essa prática. Os grandes índices de violências contra mulheres/meninas e crianças, de um modo geral, demonstram o quanto nossos/as alunos/as necessitam de um olhar atento por parte da escola, uma vez que parte significativa deles/as pode estar imersa em ambientes violentos.

Daí a importância de ouvirmos as crianças, com o intuito de perceber como elas estão, de fato, vivenciando, percebendo e sendo interpeladas pelas violências em seus lares, caso as vivenciem, uma vez que tais situações acabam se refletindo diretamente na escola. Torna-se, portanto, uma das tarefas da instituição escolar investir em uma cultura de respeito e de paz, dentro dos princípios fundamentais dos Direitos Humanos. 
Desde a Constituição Federal de 1988, tem sido delegada à escola uma série de conteúdos e questões a serem abordadas em seu currículo. Na cultura atual, a escola vem sendo afetada por um conjunto de pressões que interpela toda a comunidade escolar, desde os/as gestores/as, professores/as até alunos/ as e famílias, pois ela está no centro de inesgotáveis discussões sobre quais temas devem ou não ser abordados na escola. Além dos inúmeros questionamentos que rondam o território escolar, como, quando e o que "deve ser ensinado": quais as metodologias devem ser utilizadas, quais conteúdos contemplar. Os/as próprios/as professores/as se veem mergulhados em incertezas sobre o quê ensinar e sobre a função da escola.

Outro fato relevante desse panorama que reflete na profissão docente é que professores/as se encontram cada vez mais imersos em situações de desgaste a desvalorização e, ao mesmo tempo, necessitam estar em constante processo de formação, visto que não é possível estar à frente de uma turma sem a atualização acerca de temas e práticas contemporâneas.

Nesse processo de formação, torna-se fundamental que os/as docentes compreendam a necessidade de se estudar os Direitos Humanos na escola pública, pois não se trata apenas de "inserir mais um componente, mas de agregar diversos conteúdos, objetivos e estratégias educacionais e políticas já presentes no ambiente escolar no interior de uma robusta preocupação com os Direitos Humanos" (FACHINETTO; SEFFNER; SANTOS, 2017, p. 11).

Quando se fala sobre a necessidade de docentes compreenderem a importância dos Direitos Humanos no âmbito escolar, é relevante que esses percebam os marcadores sociais das diferenças, como as questões de gênero, étnico raciais, orientação sexual, deficiências, classe social e pertencimento religioso. Nesse território, na sociedade atual, sob uma lógica que hierarquiza e exclui, alguns desses temas são vistos como "inapropriados" no ambiente escolar, como as questões de gênero que foram suprimidas do Plano Nacional de Educação (2014/2024) e da maioria dos planos estaduais e municipais de educação. Assim, ancorados em argumentos religiosos e essencialistas, parlamentos e tribunas adotam os discursos e efeitos dessa prática excludente. Nessa direção, conforme comentam Marlucy Paraíso e Maria Caldeira (2018, p. 14), são

Tempos hostis. [...] Tempos em que grupos reacionários escolheram os currículos e as escolas para controlar de perto e impedir que os temas gêneros e sexualidades sejam trabalhados, discutidos, problematizados. Tempos em que gêneros, feminismos e sexualidades estão mais presentes do que nunca nas mídias, nas igrejas, nos partidos políticos, nas páginas policiais, nas montagens grotescas de vídeos e cartilhas divulgados por grupos religiosos e reacionários em diferentes espaços, inclusive na escola. 
Tal cenário de pânico moral tem se pautado em afirmações equivocadas e alarmistas que colocam as questões de gênero na escola como sinônimo de "perversão", acusando professores/as de serem aliciadores de crianças. Esse fato, além de representar desconhecimento sobre o tema, representa uma tentativa de tornar a escola um espaço indiferente à discriminação e à violência (SIMIONI, 2017, p. 87).

Como destaca Paraíso (2018, p. 31), além da retirada do termo "gênero" do PNE, há outros Projetos de Lei na Câmara que tentam proibir a discussão nas escolas, inclusive com previsão de pena de prisão de 6 meses a 2 anos para professores/as que trabalharem com essa temática. Outro foco das discordâncias sobre o tema na escola circula em torno do termo "Ideologia de gênero" que, conforme aponta Jimena Furlani (2016), foi utilizado pelas igrejas católicas e evangélicas de caráter mais conservador e dogmático, em meados dos anos 90 a 2000, com o intuito de barrar propostas políticas, sociais e pedagógicas com vistas ao respeito à diversidade. Tal combate contra as temáticas de gênero teve início, como destaca Rogério Junqueira Diniz (2017), em função do avanço das agendas feministas, despertando na igreja católica a construção de estratégias para barrar as conquistas das mulheres e dos grupos LGBTTI+.

No entanto, o que tem ancorado os trabalhos e as discussões sobre as questões de gênero na escola é o Parecer CNE/CP No: 8/2012, que versa sobre as Diretrizes Nacionais para a Educação em Direitos Humanos. Logo nas primeiras páginas do documento consta o seguinte:

O Parecer CNE/CEB n 5/2011 que fundamenta essas diretrizes reconhece a educação como parte fundamental dos Direitos Humanos. Nesse sentido, chama a atenção para a necessidade de se implementar processos educacionais que promovam a cidadania, o conhecimento dos direitos fundamentais, o reconhecimento e a valorização da diversidade étnica e cultural, de identidade de gênero, de orientação sexual, religiosa, dentre outras, enquanto formas de combate ao preconceito e à discriminação (BRASIL, 2012, p. 7)

Além disso, no ano de 2015, a Assembleia Geral da Organização das Nações Unidas (ONU) adotou o documento Transformando Nosso Mundo: a Agenda 2030 para o Desenvolvimento Sustentável, que apresenta 17 objetivos e 169 metas em três dimensões do desenvolvimento sustentável, que são a econômica, a social e a ambiental. Este documento versa sobre diversas tarefas que os governos, a sociedade civil, o setor privado e cidadãos deverão cumprir rumo a um 2030 sustentável. Dos 17 objetivos do documento, o quinto trata da "igualdade de gênero" e seu principal alvo é alcança-la, empoderando todas as mulheres e meninas. No site da Plataforma Agenda 30 consta que "a igualdade de gênero não é 
apenas um direito humano fundamental, mas a base necessária para a construção de um mundo pacífico, próspero e sustentável". Ainda no mesmo documento é destacado que:

Os Objetivos de Desenvolvimento Sustentável visam intensificar estas realizações, não apenas nas áreas de saúde, educação e trabalho, mas especialmente no combate às discriminações e violências baseadas no gênero e na promoção do empoderamento de mulheres e meninas para que possam atuar enfaticamente na promoção do desenvolvimento sustentável [grifo meu], por meio da participação na política, na economia, e em diversas áreas de tomada de decisão. 0 desenvolvimento sustentável não será alcançado se as barreiras tangiveis e intangíveis que impedem o pleno desenvolvimento e exercício das capacidades de metade da população não forem eliminadas (PLATAFORMA AGENDA 30).

A pesquisadora Patrícia Abel Balestrin (2017, p. 11) chama atenção para o fato de que "diversos movimentos e ações têm reafirmado a relevância dessas temáticas e a necessidade de um empenho coletivo para superarmos todas as formas de discriminação e violência existentes em nossa sociedade e em nossas escolas".

Porém, para que essas práticas e discussões ocorram na instituição escolar, além de reconhecermos a importância dos Direitos Humanos na nossa prática e de formar e preparar docentes para tal, fazse necessário que tais profissionais se sensibilizem sobre a importância de estudar tais temas e que, além das legislações vigentes, "cada escola garanta, em seus Planos Político-Pedagógicos (PPP's), a construção de espaços de discussão e ações pedagógicas comprometidas com temas relacionados à diversidade de gênero e sexualidade" (BALESTRIN, 2017, p. 13).

Segundo Felipe (2018, p. 238), "os scripts [de gênero] podem ser entendidos como composições, tramas sutis e ao mesmo tempo complexas, quase sempre negociáveis que integram, embasam e constituem as identidades de gênero e as identidades sexuais". Justificamos a afirmação recorrendo à Guacira Lopes Louro (1999, p. 17), quando diz que "a escola pratica a pedagogia da sexualidade, o disciplinamento dos corpos. Tal pedagogia é muitas vezes sutil, discreta, contínua, mas, quase sempre, eficiente e duradoura".

Assim, com formação docente e sensibilização sobre a importância das discussões de gênero e violências na escola como uma questão de Direitos Humanos, talvez seja possível revertermos algumas posturas que o próprio ambiente escolar, por vezes pratica, conforme destaca Louro (1999), sobre o 
disciplinamento dos corpos e regulação dos sujeitos. Talvez seja possível que a escola seja (ou ainda venha a ser) um lugar de escapes, de equidade, solidariedade e paz (porque acreditar nisso é preciso).

Quando se fala na necessidade de a escola incorporar em seu currículo e em sua prática essas temáticas, não há como não levar em conta que, embora o magistério seja uma profissão majoritariamente feminina, "o currículo é racional e masculinamente pensado e elaborado por homens, com a lógica masculina" (PARAíSO; CALDEIRA, 2018, p. 16). Assim, as histórias e as culturas das mulheres permanecem em "campos de silêncio", muitas vezes não sendo considerado algo importante de ser tratado na escola. Dessa forma, o "currículo é território político, ético e estético incontrolável" (PARAíSO; CALDEIRA, 2018, p. 13), e, ao mesmo tempo que pode alicerçar regulações e controle, também pode ser um território de escapes, com outras possibilidades.

A exemplo disso, a Lei 3086/2018 que passou a vigorar no município de Novo Hamburgo, região metropolitana de Porto Alegre, no dia 5 de janeiro de 2018, foi criada a partir do projeto Vereador Mirim, sendo idealizada por uma turma de crianças de uma escola da Rede Municipal de Ensino da cidade, defendida na tribuna na Câmara de Vereadores/NH por uma menina de 11 anos de idade. 0 referido projeto versa sobre a obrigatoriedade de ofertar como tema transversal, nas escolas municipais da cidade, a discussão sobre o problema da violência contra a mulher. As reuniões pedagógicas, bem como as que envolvem a comunidade, também terão a obrigação de abordar tais discussões.

Esta ação pode ser considerada como um avanço para o município. Além disso, sua implementação vai ao encontro das discussões propostas pelo sociólogo francês Bourdieu (2005), ao considerar a importância de se investir na instituição escolar, destacando ainda o papel da socialização com vistas à superação das desigualdades sociais, dentre elas as de gênero.

Porém, cabe destacar que existem outros desafios no que se refere à educação que trata dos Direitos Humanos, pois como ressaltam Antonio de Almeida Neto e Elaine Lourenço (2017), incluir os Direitos Humanos nas escolas de Educação Básica tem várias implicações, como a adequação ou até mesmo mudança nas disciplinas, nas estratégias, nos materiais didáticos. É possível observar uma grande dificuldade par levar adiante esses temas, uma vez que muitos municípios têm implementado um sistema de "apostilamento", com atividades prontas e metas a serem alcançadas pelas crianças (como por exemplo o treinamento da motricidade fina), proposta que se choca com as concepções teóricas sobre os campos de experiência para a Educação Infantil, onde a escola deve se constituir em um espaço de ações educativas mais abrangentes, não cabendo conhecimentos organizados por áreas de modo sistematizado. 
Os campos de experiências implicam em um itinerário formativo, através da individuação de cinco campos correspondentes a outros tantos mundos cotidianos de experiência, a saber: o eu e o outro; percepção e movimento; o gesto, a imagem e a palavra; os problemas, as provas, as soluções; a sociedade e a natureza.

Ao adotar o sistema de apostilamento fica evidenciada a falta de conhecimento teórico sobre o próprio desenvolvimento infantil, o que tem acarretado uma relutância para efetivar as modificações necessárias para que temas sensiveis sejam de fato discutidos na escola e na formação docente.

Como é do conhecimento daqueles que lidam com educação escolar, temas como conflitos relacionais, relações de gênero, inclusão, racismo, deficiência física, cidadania, diversidade, violência, questão étnicoracial, trabalho infantil, religião/laicidade e culturas juvenis referem-se a questões candentes com as quais os professores, alunos, pais e outros sujeitos escolares se deparam cotidianamente, da Educação Infantil ao Ensino Médio, e que, no entanto, não constam nas propostas curriculares convencionais. Racismo, violência sexual e de gênero, intolerância religiosa e discriminação existem na sociedade e na escola, todos sabem, mas frequentemente não são vistos como questões a serem tratadas no currículo, ainda que apareçam frequentemente nos discursos educacionais (NETO, e LOURENÇO, 2017).

A possibilidade de discutir tais temáticas desde a Educação Infantil, poderá contribuir no processo de desconstrução de alguns padrões que pautam os comportamentos, escolhas e atitudes de meninos e meninas. Desse modo, também será possível intervir no cenário de violências contra as mulheres no momento em que as crianças compreenderem os seus direitos e as consequências de um ambiente violento. É preciso, portanto, estimular todos/as ao diálogo e respeito para a resolução dos conflitos, dentro e fora da escola, numa relação de equidade.

Por isso, acreditamos que a discussão sobre temas sensíveis com as crianças envolve formação docente e sensibilização sobre a importância das discussões de gênero e violências na escola como uma questão de Direitos Humanos. Assim, talvez seja possivel revertermos algumas posturas que o próprio ambiente escolar, por vezes, pratica, conforme destaca Louro (1999), sobre o disciplinamento dos corpos e regulação dos sujeitos. Talvez seja possível que a escola seja (ou ainda venha a ser) um lugar de escapes, de equidade, solidariedade e paz (porque acreditar nisso é preciso).

\section{REFERÊNCIAS}

ARGÜELLO, Zandra Elisa. Contos a favor da Equidade de Gênero. In: FELIPE, Jane; GUIZZO, Bianca Salazar; BECK, Dinah Quesada. Infâncias, gênero e sexualidade nas tramas da cultura e da educação. Canoas: Ed. Ulbra, 2013. 
BALESTRIN, Patrícia Abel. Introdução aos estudos de gênero e sexualidade em articulação com o campo da educação. In: SILVEIRA, Catharina; FRIEDERICHS, Marta; SOARES, Rosângela; SILVA, Rosimeri (orgs.). Educação em gênero e diversidade. Porto Alegre: Tomo editorial, 2017.

BOURDIEU, Pierre. A dominação Masculina. Traduzido por: Maria Helena Kühner. 4.ed. Rio de Janeiro: Bertrand Brasil, 2005.

BRASIL. Estatuto da Criança e do Adolescente. Câmera dos Deputados, Lei no 8.069, de 13 de julho de 1990. DOU de 16/07/1990 - ECA. Brasília, DF.

BRASIL. Resolução CNE/CEB n 1, de 30 de maio de 2012. Estabelece Diretrizes Nacionais para a Educação em Direitos Humanos. Brasília, 2012.

BRASIL. Resolução CNE/CEB n 1, de 30 de maio de 2012. Estabelece Diretrizes Nacionais para a Educação em Direitos Humanos. Brasília, 2012.

BRASIL. Plano Nacional de Educação 2014-2024 [recurso eletrônico]: Lei n 13.005, de 25 de junho de 2014, que aprova o Plano Nacional de Educação (PNE) e dá outras providências. - Brasília: Câmara dos Deputados, Edições Câmara, 2014.

DINIZ, Rogério Junqueira. "Ideologia de gênero": a gênese de uma categoria política reacionária - ou: a promoção dos direitos humanos se tornou uma "ameaça à família natural"? . In: RIBEIRO, Paula Regina Costa; MAGALHÃES, Joanalira Corpes (org.). Debates contemporâneos sobre Educação para a sexualidade. Rio Grande: Ed. da FURG, 2017.

FACHINETTO, Rochele; SEFFNER, Fernando; SANTOS, Renan. (orgs.). Educação em Direitos Humanos. Porto Alegre: Tomo editorial, 2017.

FELIPE, Jane; GUIZZO, Bianca Salazar. Rompendo com os scripts de gênero e de sexualidade na infância. In: SARAIVA, Karla; GUIZZO, Bianca (Org.). Educação, transgressões e narcisismos. Canoas/RS: Ed. da Ulbra, 2017.p. 219 - 228.

FELIPE, Jane; GALET, Carmem; Maus-tratos emocionais e formação docente. In: LUZ, Nanci Stancki da; CASAGRANDE Lindamir Salete (org.). Entrelaçando gênero e diversidade: violências em debate. Curitiba: Ed. UTFPR, 2016. 
FILHA, Constantina Xavier. Violências e direitos humanos em pesquisa com crianças. Educ. Pesqui., São Paulo, v. 41, n. especial, p. 1569-1583, dez., 2015.

FLORES, Joaquin Herrera. A reinvenção dos direitos humanos. 2009

FURLANI, Jimena. "Ideologia de Gênero"? Explicando as confusões teóricas presentes na cartilha. Versão Revisada 2016. Florianópolis: FAED, UDESC. Laboratório de Estudos de Gênero e Família, 09 pp, 2016.

IBGE. Estatísticas de Gênero Indicadores sociais das mulheres no Brasil. In: Estudos e Pesquisas: Informação Demográfica e Socioeconômica. n.38, 2018.

IPEA. Atlas da violência 2018. Disponível em <http://www.ipea.gov.br/portal/images/stories/PDFs/ relatorio_institucional/180604_atlas_da_violencia_2018.pdf > Acesso em 02 jul. 2018.

LOURO, Guacira Lopes. Gênero, sexualidade e educação: uma perspectiva pós-estruturalista. Petrópolis: Vozes, 1999.

NETO, Antonio Simplicio de Almeida. LOURENÇO, Elaine. Direitos Humanos e cultura escolar. - 1. ed. São Paulo: Alameda, 2017.

PARAIISO, Marlucy Alves; CALDEIRA, Maria Carolina da Silva (Orgs.). Pesquisas sobre currículos, gêneros e sexualidades. Belo Horizonte: Mazza Edições, 2018.

PLAN BRASIL. Por Ser Menina no Brasil: Crescendo entre Direitos e Violências (Pesquisa com meninas de 6 a 14 anos nas cinco regiões do Brasil). São Paulo, 2014. Disponível em: www.plan.org.br/downloads/ por_ser_menina_pesquisa_relatorio_final.zip

PLATAFORMA, Agenda 30. Os 17 Objetivos de Desenvolvimento Sustentável. Disponível em < http:// www.agenda2030.com.br/ods/5/>. Acesso em 09 jan. 2018.

SIMIONI, Fabiane. Gênero na escola e democracia à brasileira: limites e desafios para uma vida livre de discriminação e violência. In: FACHINETTO, Rochele; SEFFNER, Fernando; SANTOS, Renan. (orgs.).

Educação em Direitos Humanos. Porto Alegre: Tomo editorial, 2017.

TURIN, Adela. Arturo y Clementina. Traducción: Humpt Dumpty. Barcelona: Editorial Lúmen, S.A., 2001. WAISELFISZ, Julio Jacobo: Mapa da violência 2015: homicídio de mulheres no Brasil. $1^{\text {a }}$ Edição Brasília DF, 2015. 